\title{
Multimodal Approach to Identify Learning Strategies of Visual and Verbal Learners
}

\author{
https://doi.org/10.3991/ijet.v12.i10.6935 \\ Mahendra A Sethi $\left.{ }^{\square}\right)$ \\ Dr. BAM University, Aurangabad, India \\ mahindrra@gmail.com \\ Santosh S Lomte \\ VDF School of Engg \& Technology Latur, India \\ Ulhas B Shinde \\ Dr. BAM University, Aurangabad, India
}

\begin{abstract}
This paper presents a multimodal approach to identify visual or verbal learning style and learning strategies of visual and verbal learner. A web based tool is developed to deliver the V-Square test and LST Test. V-Square identifies visual and verbal learners. It is based on visual/verbal dimension of Felder Silverman Model. Learning strategy test (LST) identifies the learning strategies of the learners. LST test uses questions associated with aural and read/write dimensions of VARK model. This paper summarizes implementation of method, algorithms and data analysis of participants collected from web based tool in an eLearning environment and manual test.
\end{abstract}

Keywords-Learner Style, Learning Strategies, Learning assessment strategies, visual learner, verbal learner, FSLSM, VARK

\section{Introduction}

Learning styles and learning style models are explored by researchers since a long time. In recent years eLearning has gained attention of researchers as it is widely used in education and industry for training. Most of the work carried out on learning styles tries to identify various patterns, behaviors to deduce learning styles in Learning Management Systems. Felder Silverman Learning Style model is widely used in such research studies. There are four dimensions of learning style in FSLSM. Researchers have explored all dimensions of FSLSM still there is scope for investigating visual / verbal dimension of FSLSM, particularly for designing web based eLearning systems. In a web, based eLearning environment content plays an important role in learning. In such learning environment audio, visual contents are delivered mostly. Some environment like "youtube" provide video contents, either recorded, simulated etc. Some environment provides only text and graphics. Contents suitable to learner style can enhance the learning efficiency. Hence there is need of identifying the preference of 
learner on visual and verbal dimension. This paper describes the multimodal approach based on Felder Silverman Learning Style Model and VARK model. In this approach two important algorithms are implemented. The "Learner Style Clustering" algorithm presents the "V-Square" test to learners and clusters them into three learning styles discussed in section 5. The "Learning Strategy" algorithm presents "LST Test" to learner and assigns the detected learning strategy to learner profile as discussed in section 7. The identification of learning style and learning strategies will help teachers, instructional designers to design effective and style specific contents that can be delivered to the learners and creates the opportunity to improve the learning performance and effective utilization of web based eLearning Systems.

\subsection{Research Method}

The research is aimed to achieve three important objectives. First is to identify and create the clusters of visual and verbal learners using ILS Questionnaire in Felder Silverman Learning Style Model. The second objective is, to identify the learning strategies of visual and verbal learners using VARK questionnaire. Third objective is to test reliability of the proposed approach using a test-retest approach.

Two separate tests called "V-Square test" and "Learning Strategy Test" (LST) are designed to achieve the objective of the research. The participants are asked to appear the test twice. Initially all the participants appeared for a manual test, taken using paper and pencil. Later on, after a gap of 15 days' same participants are asked to appear for the system test developed in web based eLearning system called "IDEL". The web based eLearning System is developed using HTML, CSS, Javascript, Ruby language and Postgresql database is used to maintain and manage the learner profiles. The results of manual test and system test are used to test reliability of the proposed approach.

\subsection{Participants}

62 participants of second year engineering studying a compulsory undergraduate course on "Data Structure" from Dr. Babasaheb Ambedekar Marathwada University were examined.

\subsection{Data Collection Instruments}

The data used for research is obtained through system test and manual test. VSquare Test and LST Test are designed to achieve the above stated objectives. These tests serves as an instrument for data collection in manual and system test of learner. The data obtained using manual test is separately stored using an Excel Sheet and used to compare with the data obtained through system test taken in a web based eLearning environment. 


\section{Related Work}

During learning in classroom or in an eLearning Environment, individual has a particular preference for receiving and processing information which is called as learning style. In 1988, Richard M. Felder and Linda K. Silverman proposed a learning style model that contains five categories of learning style in which learner may fall and have more or less preference to a learning dimension in that category. Later on, in 2002 Felder in his preface mentioned the reasons to delete inductive and deductive dimension and changing visual / auditory dimension to visual / verbal dimension [1], [2].

In an informal survey of engineering students and professors to identify the learning style, it is revealed teaching style of many of the professors does not match the learning style of students. Even professors accepted the same. Most of the students have preference towards visual, sensing, inductive and active learning dimensions whereas few are creative and has preference towards global learning. Students showed preference towards intuitive, auditory, deductive and sequential. The professors were unable to match these preferences [1]. The model also suggested teaching strategies for each category. Learning strategies for each preferred dimension of Felder Silverman learning style models are mentioned in [3].

In 1991 Richard Felder and Barbara Solomon has created 44 questions set termed as Index of Learning Style Questionnaire. The ILS questionnaire finds the preference of learner on four dimension of Felder Silverman Learning Style Model [4]. The web version of ILS Questionnaire is available at [5]. The ILS questionnaire along with scoring sheet and report form is available at [6]. Reliability and validity of ILS Questionnaire on different aspects is done in [7], [8], [9], and [10].

VARK is one of the catalysts learning style model that helped researchers to deduce how individual learns and how to enhance learning process. In 1987 Neil Fleming introduced learning style model for visual, aural, read/write and kinesthetic preferences [12]. In 1992 Neil D. Fleming and Colleen Mills designed a technique to address students learning preferences in which a set of 13 questions was used [11]. Later on, one more preference called multimodal was introduced to cater the needs of learners having multiple preferences for learning. VARK is popular tool in Western Part of the world as it is easy to use; it provides help sheets for learners, instructors and other users like employers, employees. Recent version developed in 2006 contains 16 Questions and four options for answers whose wording is according to $21 \mathrm{st}$ century. VARK's specialist versions are also available to judge athletes and younger of age 12-18 years [12].

Learning Style of a learner can be identified explicitly or implicitly. Explicit approach makes use of questionnaires developed to identify learning style for a specific learning style model it is also known as collaborative approach. The frequently used questionnaire and learning style model in this approach includes ILS Questionnaire to detect learning style based on Felder Silverman Learning Style Model, Learning Style Inventory (LSI) is used with Kolb's Learning style model, Group Embedded Figure Test for Witkin's CS model, Learning style questionnaire is an alternative to LSI used with Kolb's Learning style model, Cognitive Style Index (CSI) questionnaire is used 
to identify intuitive and analytical learners, Cognitive Style Analysis (CSA) Test is used to find Wholist/ Analytical (WA) and Verbal/ Imagery (VI) learners in Cognitive Style Model developed by Riding and Cheema [13]. Simon Casidy has given overview of various learning style assessment questionnaires associated with learning style models in [14].

Implicit approach is further divided into two categories data driven approach and literature based approach. Data driven approach makes use of techniques such as Bayesian Networks, Artificial Neural Network, Decision Trees and Hidden Markov Model. Whereas literature based approach identifies pattern - behavior relationship to identify learner style. Both approaches are quite similar [13]. Implicit approach provides a limited scope to instructor for developing style specific learning objects rather helps to determine learning strategies.

Ali Alharbi etl... examined 38 students learning the course on "programming languages concept and paradigm". The learning styles were evaluated using ILS Questionnaire. To evaluate self-regulated learning strategies of students Motivated Strategies Learning questionnaire was used. Through a descriptive analysis study variables were examined using mean, standard deviation and charts. Pearson's product moment correlation coefficient is used to perform correlation analysis among the study variables [15].

In an analysis presented by Silvia Rita Viola etl... using data driven approach on ILS questionnaire presented to 207 individuals revealed that the answer for active style questions are relevant to visual style. The authors discussed the results of classical correlation and multivariate analysis. Multiple Correspondence Analysis was cross validate using the Pearson's correlation coefficients and related $p$ values of the matrix of relative frequencies per style. In order to guarantee a minimal comparability with other results, Principal Component Analysis (PCA,) was performed on ILS 44 items matrix $M$ using Singular Value Decomposition (SVD). In the analysis authors claimed two points. First, the "active and visual" dimensions and "sequential and sensing" dimensions are highly correlated. Second, all other dimensions are independent [16].

Norasmah Othman and Mohd Hasril Amiruddin discussed the advantages of VARK in [17]. The learning styles are useful to identify learning environment suitable to learners instead means for involving intelligence or skills. VARK enables to understand how one can pursue new knowledge or understand the instruction. VARK contributes to stimulate learning senses of a learner [17].

In a research study conducted to identify learning styles of engineering students of different department Burcu Devrim Ictenbas, and Hande Eryilmazb used VARK Questionnaire. 107 students out of 120 students solved the VARK test. The study has shown that learning styles are important in gaining maximum learning benefit from a course. The results revealed that $25 \%$ students are inclined / having more preference towards multimodal learning styles [18].

In a study conducted by Julie Willems to provide direction for e-educators or instructional designers, ILS questionnaire was presented to novice undergraduate eLearners, Graduate e-Learners and e-educators. During the study, quantitative and 
qualitative analysis was presented to suggest the various learning elements that can be included into an eLearning course [19].

In an experiment conducted by Pham Quang and Adina Magda Florea, a web based eLearning System (POLCA) detects learning style from ILS questionnaire to deliver the adaptive contents. The ILS test was optional in this system. A simple mapping rule base method is implemented to gather learner behavior data to deduce the learning style for adaptive content delivery. The authors claim that the method can be used with any LMS [20].

Thomas Lehmann and Dirk Ifenthaler, conducted a study to find a starting point for creating instructions for the targeted group using problem scenarios and prompts, domain specific knowledge test and German translation of ILS questionnaire. In this study 56 participants participated out of which 47 were identified as visual and 9 were identified as verbal. For analysis reference model and HIMATT tool was used [21].

Emel Ultanir etl... has presented a study aimed towards reliability and validity of the ILS instrument translated into Turkish. Language and content validity is carried out to study the reliability and validity. The most preferred learning styles were identified as sequential, sensory and active [22].

Maryam Yarandi etl... has presented a personalized e-learning system that creates contents according to abilities, learning style and knowledge level of learner. The authors used ILS Questionnaire and Ontology based approach for personalization. The system included three model viz learner model, domain model and content model. Tailored contents are delivered to learners based on learner's characteristics using content model and learner model [23].

Juan Yang etl... has proposed an approach to dynamically find the learner style using information patterns. The authors implemented a method that predicts the learning style by observing critical learning behavior. The system creates clusters of learner according to learning style. To verify the system predicts and creates the desired clusters 30 students were asked to complete the ILS questionnaire and results were compared. The author's claim that the learning style predication accuracy of approach is high as compare to previous studies [24].

Jennifer Beckmann etl... used FSLSM and ILS questionnaire to develop "Adaptive eLearning based on individual learning styles -Performance and emotional factors" [25]. Milan Klement presented a study aimed at identifying learning styles and distributing the respondents according to age group. Frequencies for particular preference upon VARK are analyzed with additional information of learner such as age [26].

Jingyun Wang and Takahiko Mendori, presented an analysis of reliability and validity of ILS instrument translated in Mandarin for a language learning system. The study suggests that Mandarin version satisfies the criterion of acceptability. The resultant data was also used to compare the learning style of engineering students and language students. The study also reveals that gender characteristics does not play role in identification of learning style [27]. S. Muruganandam and N. Srinivasan, has discussed the appraisal of FSLS model using the two discrete data sets of full time and part time students. Based on the study author's drawn interpretations as full time 
students have all learning styles whereas part time students preferred auditory and visual learning style [28].

Some of the recent studies on Felder Silverman learning style model are available in literature includes [29], [30], [31], [32], [33] and [34]. These studies use data, behavior or other characteristics to identify learning style in an adaptive learning environment. More details on studies recently published are available in [35], [36] and [37] which are related to VARK model but used to implement adaptive eLearning Systems with various approaches apart from questionnaire.

\section{Proposed Multimodal Approach}

To carry out the research a web based "Interactive Dynamic eLearning Framework for Visual and Verbal Learners" (IDEL) is under development using HTML, CSS, JavaScript, Ruby and PostgreSQL. The figure shows the system architecture of the proposed framework which is intended to discover learner style, learning strategies, learning assessment strategies and deliver the style specific learning objects.

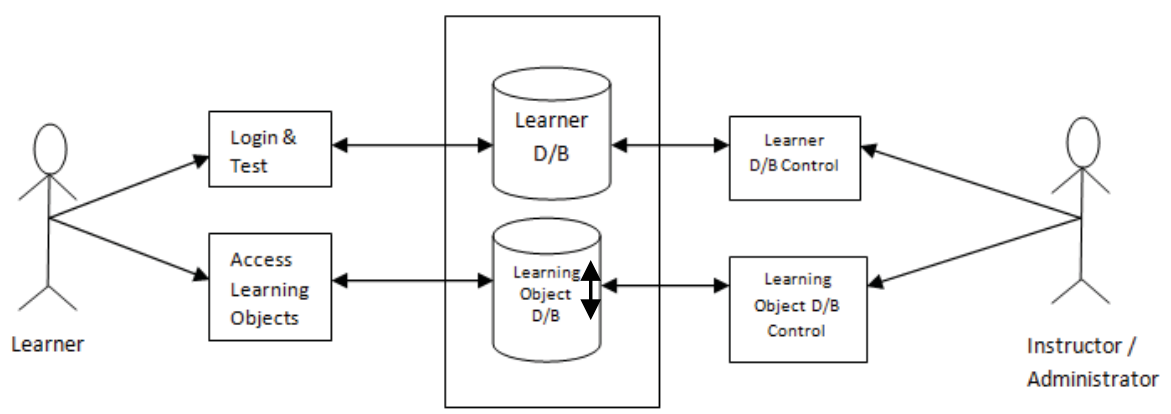

Fig. 1. Proposed System architecture of IDEL

As mentioned earlier, the web based tool first presents V-Square Test (VST) to learner for determining the visual or verbal learning style. Once the learner completes the VST, the system uses recorded answers to identify the visual and verbal learner. The system then automatically creates three clusters of learners as visual learners, verbal learners and balanced learners. The cluster formation algorithm is discussed in detail in section 5.2.

After completion of VST, Learning Strategy Test (LST) is presented to learner for identification of learning strategy. The test identifies whether a learner is active listener, active reader or balanced listener $\&$ reader.

VST is based on ILS Questionnaire that identifies visual and verbal preference of Felder Silverman Learning Style Model. LST is based on VARK questionnaire that helps to find listening and reading preferences of learner in Aural and Read/Write dimensions of the VARK Model.

Learning Style Clustering algorithm, Learning Strategy algorithm and Learning Assessment Strategy algorithm are the important components of the proposed frame- 
work. The following section highlights the important tasks implemented in first two components.

\section{$4 \quad$ Visual and Verbal Learning Style}

In Felder Silverman Learning Style model, Visual / Verbal is one of the dimension to which a learner can have more or less preference. In most of the studies found in literature suggest visual / verbal is more preferred dimension when it comes to find learning style. In an eLearning environment, the learning contents are provided in the form of text, graphics, images, sound, video etc. Hence our focus is to implement the system that will identify visual and verbal learners, their learning strategies, learning assessment strategies and accordingly will deliver style specific learning objects.

\section{$5 \quad$ Learner Style Clustering Algorithm}

The learner style clustering algorithm is implemented to perform two important tasks. Initially it identifies the learning style intensity (LSI) of a learner on his / her preferred dimension. The LSI is assigned to a learner profile. Later on, it creates three learning style clusters viz, visual, verbal and balanced.

\subsection{Learning Style Intensity (LSI)}

The V-Square test is used to identify learner style intensities. Learner style intensities are defined in following table as mentioned in [4], [5], and [6].

Table 1. Learning Style Intensities

\begin{tabular}{|l|l|}
\hline \multicolumn{1}{|c|}{ LSI Pointer } & \multicolumn{1}{c|}{ Learning Style Intensities } \\
\hline $9 \mathrm{a}$ to $11 \mathrm{a}$ & Visual \\
\hline $9 \mathrm{~b}$ to $11 \mathrm{~b}$ & Verbal \\
\hline $1 \mathrm{a}$ to $3 \mathrm{a}$ or $1 \mathrm{~b}$ to $3 \mathrm{~b}$ & Visually \&Verbally Balanced \\
\hline $5 \mathrm{a}$ to $7 \mathrm{a}$ & Visually Inclined \\
\hline $5 \mathrm{~b}$ to $7 \mathrm{~b}$ & Verbally Inclined \\
\hline
\end{tabular}

The V-Square Test contains 11 questions [Q3, Q7, Q11, Q15, Q19, Q23, Q27, Q31, Q35, Q39, Q43] and two possible answers either "a" or "b" to each question taken from ILS Questionnaire [6]. During the test the learner is asked to select either of the two options. The algorithm counts the total number of selected preferences among "a" and "b" for all the 11 questions. It is called as sum of preferences (SOP). The two counters SOP_a and SOP_b is given using the following equation.

$$
\mathrm{SOP}=\sum_{\mathrm{Qi}=1}^{\mathrm{n}} \mathrm{Xi}
$$

Where, 
"Qi" is the question number and $\mathrm{n}=11$.

"Xi" is all "a / b" i.e. the option selected by learner for all questions "Qi".

The learning dimension scale value is found by subtracting the smaller SOP value from larger SOP value using equation 3.

$$
\text { LDS }=\text { Larger SOP }- \text { Smaller SOP }
$$

The learning style intensity pointer is obtained by writing the letter of larger SOP in front of learning dimension scale value.

$$
\text { LSIP }=\text { LDS (letter of larger SOP) }
$$

The algorithm assigns one of the LSIP to the learner profile upon completion of VSquare Test. The possible values of LSIP and Learning style intensities are shown in table 1.

\subsection{Formation of Learner Style Clusters:}

Once the learner is assigned LSI, the algorithm creates three clusters as per the classification given in table 2 and the learner belongs to any one of the cluster.

Table 2. Learner Style Clusters

\begin{tabular}{|l|l|}
\hline \multicolumn{1}{|c|}{ Learner Style Cluster } & \multicolumn{1}{c|}{ Learner Style Intensity } \\
\hline Visual (VIS) & Visual \\
\hline Verbal (VRB) & Verbal \\
\hline \multirow{2}{*}{$\begin{array}{l}\text { Visually \& Verbally Balanced } \\
(\text { VVB) }\end{array}$} & Visually \&Verbally Balanced \\
\cline { 2 - 2 } & Visually Inclined \\
\cline { 2 - 2 } & Verbally Inclined \\
\hline
\end{tabular}

Cluster of Visual Learners (VIS). All the learners having "Visual" Learning Style Intensity are included in this cluster.

Cluster of Verbal Learners (VRB). All the learners having "Verbal" Learning Style Intensity are included in this cluster.

Cluster of Visually and Verbally Balance Learners (VVB). This cluster contains all learners whose Learning Style Intensities are "Visually and verbally balanced", "Visually inclined" and "Verbally inclined". The learner's LSI pointer value is any one among 1a, 3a, 5a, 7a, 1b, 3b, 5b, or 7b.

Finally, the learner will have any one of the learning style as shown in figure 2. 


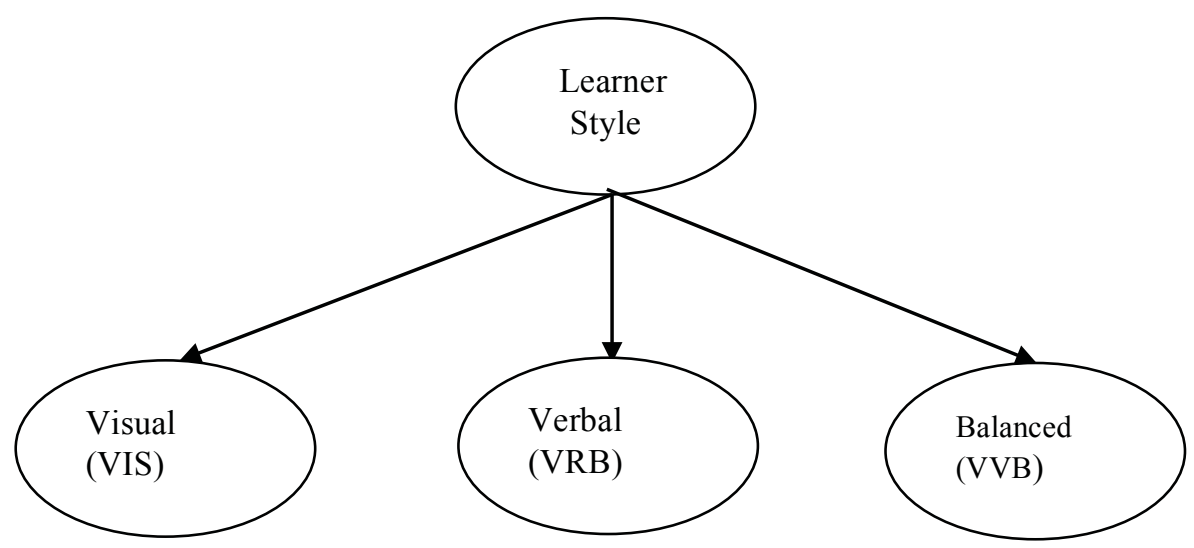

Fig. 2. Learning Style Clusters

\section{$6 \quad$ Learning Strategies}

This is the second step in the proposed framework. Learning style and learning strategies are quite different in nature. Intention to identify learning strategies is to deduce a precise learning strategy of visual, verbal and balanced learner. During learning in an ILT, WBT or CBT environment a learner may have preference for receiving information through listening / heard instruction which shows that a learner is interested in listening more. Similarly, a learner may like to read text written on board, printed on paper or displayed on screen which shows that a learner is more interested towards reading. It is also possible that the learner may have moderate preference for listening and reading. Thus, three possible learning strategies are discussed below.

\subsection{Active Listener}

A learner is an active listener if he prefers to listen more. This type of learner learns through spoken instructions. The instruction may be delivered by a teacher or it can be delivered through the recorded audio sound.

\subsection{Active Reader}

A learner is an active reader if he prefers to read the instructions / learning material from book, printed material, written text on screen, written text on board etc. 


\subsection{Balanced Listener \& Reader}

When learner has moderate preferences over the both dimensions then the learner is balanced listener and reader.

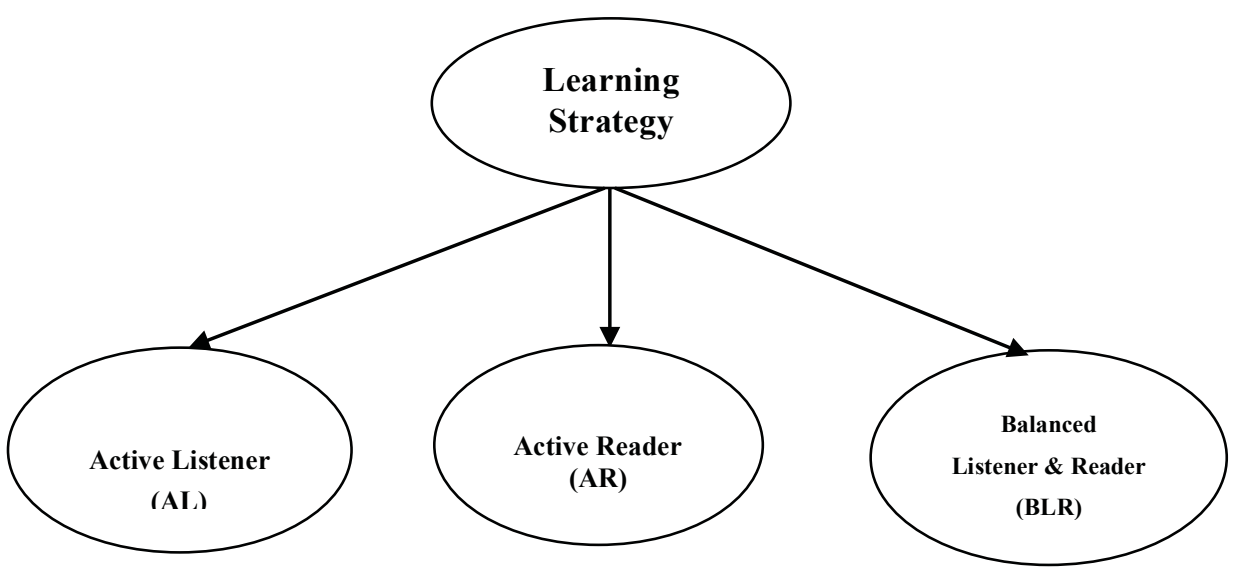

Fig. 3. Learning Strategies

\section{$7 \quad$ Learning Strategy Algorithm}

This is the second step in the proposed framework. The learning strategy algorithm is implemented to perform two important tasks. Initially it identifies the learning strategies (LST) of a learner on his / her preferred dimension. The preferred LST is assigned to a learner profile. Later on, it creates three learning strategy clusters viz, active listener, active reader and balanced reader and speaker.

\subsection{Learning Strategy Intensity}

The VARK Questionnaire is developed by Neil Fleming that helps to identify the learners having preferences in Visual, Aural, Read/Write and Kinesthetic sensory modalities [12]. It is set of 16 questions with four options. The interest is to find the listening or reading preference, hence the set of questions used in Learning Strategy Test considers only two options for Aural and Read preferences. Learning Strategy Test (LST) is constructed using 10 Questions (Q4, Q6, Q7, Q8, Q9, Q10, Q11, Q12, Q13, and Q15) of VARK Questionnaire and the sequence is renamed.

This test identifies the learner's preference over listener and reader dimension. The test contains 10 questions and two possible answers either "a" or " $b$ " to each question. During the test the learner is asked to select either of the two options. The algorithm counts the total number of selected preferences among " $a$ " and " $b$ " for all the 10 questions. It is called as sum of preferences (SOP). The two counters for learning strategy preferences are "LST_SOP_a" and "LST_SOP_b" are calculated using the equation 4. 


$$
\mathrm{LST}_{-} \mathrm{SOP}=\sum_{\mathrm{Q} \mathrm{i}=1}^{\mathrm{n}} \mathrm{Xi}
$$

Where,

"Qi" is the question number and $\mathrm{n}=10$.

"Xi" is all "a or b" i.e. the option selected by learner for all questions "Qi".

The learning strategy dimension scale value is found by subtracting the smaller LST SOP value from larger LST SOP value.

$$
\text { LST_LDS }=\text { LargerLST_SOP }- \text { Smaller LST_SOP }
$$

The learning strategy intensity pointer is obtained by writing the letter of larger LST_SOP in front of learning strategy dimension scale value.

$$
\text { LST_IP = LST_LDS (letter of larger LST_SOP) }
$$

The algorithm assigns one of the LST_IP to the learner profile upon completion of LST Test. The possible values of LST_IP and Learning strategy intensities are shown in table 3 .

Table 3. Learning Strategy Intenstiy.

\begin{tabular}{|l|l|}
\hline \multicolumn{1}{|c|}{ LST_IP (Pointer) } & \multicolumn{1}{c|}{ Learning Strategy Intensity } \\
\hline $0 \mathrm{a}$ to $2 \mathrm{a}$ or $0 \mathrm{a}$ to $2 \mathrm{~b}$ & Fairly Balanced \\
\hline $4 \mathrm{a}$ to $6 \mathrm{a}$ & Inclined toward Listening \\
\hline $4 \mathrm{~b}$ to $6 \mathrm{~b}$ & Inclined towards Reading \\
\hline $8 \mathrm{a}$ to $10 \mathrm{a}$ & Listener \\
\hline $8 \mathrm{~b}$ to $10 \mathrm{~b}$ & Reader \\
\hline
\end{tabular}

\subsection{Formation of Learning Strategy Clusters}

Once the learner completes the test, depending upon the learning dimension scale value pointer, the learner belongs to any one of the identified learning strategy cluster.

Cluster of Active Listeners (AL). This cluster contains all learners who have strong preference for learning through Listening which is calculated using equation 7.

$$
\mathrm{AL}=\mathrm{AL} \_1+\mathrm{AL} \_2
$$

Where,

AL_1 is a number of learners whose LST_IP value is 8a.

$\mathrm{AL}_{-} 2$ is a number of learners whose LST_IP value is $10 \mathrm{a}$.

Cluster of Active Readers (AR)

This cluster contains all learners who have strong preference for learning through Reading which is calculated using equation 8.

$$
\mathrm{AR}=\mathrm{AR} \_1+\mathrm{AR} \_2
$$

Where, 
AR 1 is a number of learners whose LST_IP value is $8 \mathrm{~b}$.

$\mathrm{AR}^{-} 2$ is a number of learners whose $\mathrm{LST}^{-}$IP value is $10 \mathrm{~b}$.

Cluster of Balanced Listeners and Readers (BLR). This cluster contains all the learners who have balance preference for learning through Listening and Reading and it is calculated using equation 9.

$$
\text { BLR }=\text { FB_LR+IN_L }+ \text { IN_R }
$$

Where,

FB_LR is number of learners having fairly balanced preference for learning through listening and reading; having LST_IP values between $0 \mathrm{a}$ to $2 \mathrm{a}$ and $0 \mathrm{~b}$ to $2 \mathrm{~b}$.

IN_L is the number of learners inclined towards learning through listening and having learning LST_IP values $4 \mathrm{a}$ or $6 \mathrm{a}$.

IN_R is the number of learners inclined towards learning through reading and having LST_IP values $4 \mathrm{~b}$ or $6 \mathrm{~b}$.

The following table shows the three possible learning strategy clusters according above equations.

Table 4. Learning Strategy Clusters.

\begin{tabular}{|l|l|}
\hline \multicolumn{1}{|c|}{ Learning Strategy Clusters } & \multicolumn{1}{c|}{ Learning Strategy Intensity } \\
\hline Active Listener (AL) & Listener \\
\hline Active Reader (AR) & Reader \\
\hline \multirow{3}{*}{ Balanced Listener \& Reader (BLR) } & Fairly Balanced \\
\cline { 2 - 2 } & Inclined toward Listening \\
\cline { 2 - 2 } & Inclined towards Reading \\
\hline
\end{tabular}

Thus, as per the clusters shown in table 4 finally the algorithm assigns any one of the learning strategy depending upon the value of learning strategy intensity pointer. From table 2 and table 4 to we can deduce that each learner has a learning style and a learning strategy associated with it. The learning strategies for each learning style cluster are shown below.

Table 5. Learning Strategies of Visual, Verbal and Balanced Learners.

\begin{tabular}{|l|l|l|l|}
\hline \multicolumn{1}{|c|}{ Learning Strategy Cluster } & \multicolumn{1}{|c|}{$\begin{array}{c}\text { AL } \\
\text { (Active Listener) }\end{array}$} & \multicolumn{1}{c|}{$\begin{array}{c}\text { BLR } \\
\text { (Active Reader) }\end{array}$} & $\begin{array}{l}\text { BLR } \\
\text { (Listener \& Read- } \\
\text { er) }\end{array}$ \\
\hline Visual & LST_1 & LST_2 & LST_3 \\
\hline Verbal & LST_1 & LST_2 & LST_3 \\
\hline Balanced & LST_1 & LST_2 & LST_3 \\
\hline
\end{tabular}

Learning Strategies of Visual Learners. From table 5 we can deduce that the visual learners will adopt one out of three learning strategies. 
Learning Strategy 1 (LST_1). The visual learner will learn easily if the learner gets a learning environment in which the learning contents are visual oriented, and provides more scope for listening.

Learning Strategy 2 (LST_2). The visual learner will learn easily if the learner gets a learning environment in which the learning contents are visual oriented, and provides more scope for reading.

Learning Strategy 3 (LST_3). The visual learner will learn easily if the learner gets a learning environment in which the learning contents are visual oriented, with equal scope for listening and reading.

Learning Strategies of Verbal Learners. From table 5 we can deduce that the Verbal learners will adopt one out of three learning strategies.

Learning Strategy 1 ( $L S T_{-}$1). The verbal learner will learn easily if the learner gets a learning environment in which the learning contents are verbal oriented, and provides more scope for listening.

Learning Strategy 2 (LST_2). The verbal learner will learn easily if the learner gets a learning environment in which the learning contents are verbal oriented, and provides more scope for reading.

Learning Strategy 3 (LST_3). The verbal learner will learn easily if the learner gets a learning environment in which the learning contents are verbal oriented, with equal scope for listening and reading.

Learning Strategies of Visually \& Verbally Balanced Learners. From table 5 we can deduce that the visually and verbally balanced learners will adopt one out of three learning strategies.

Learning Strategy 1 (LST_1). The learner will learn easily if the learner gets a learning environment in which the learning contents are visually and verbally balanced, and provides more scope for listening.

Learning Strategy 2 (LST_2). The learner will learn easily if the learner gets a learning environment in which the learning contents are visually and verbally balanced, and provides more scope for reading.

Learning Strategy 3 (LST_3). The learner will learn easily if the learner gets a learning environment in which the learning contents are visually and verbally balanced, with equal scope for listening and reading.

\section{$8 \quad$ Results}

In manual test total 62 students appeared for the "V-Square" and "LST" test. The count of visual learners and verbal learners is less still the approach can be useful for designing the instructions and learning experience for the learners. The following section summarizes the results of manual test.

\subsection{Results of Manual V-Square Test}

As shown in Graph 1 the visual learning style cluster contains 21 learners, verbal learning style cluster contains 6 learners and remain 35 learners which have moderate 
preferences on both dimensions are grouped in balanced cluster as mentioned in section 5.2 manually. Thus $33.87 \%$ learners were identified as visual learners, whereas only $9.68 \%$ learners were having strong preference in verbal dimensions. The results show that maximum learners i.e. $56.45 \%$ have moderate preference on the visual and verbal dimensions.

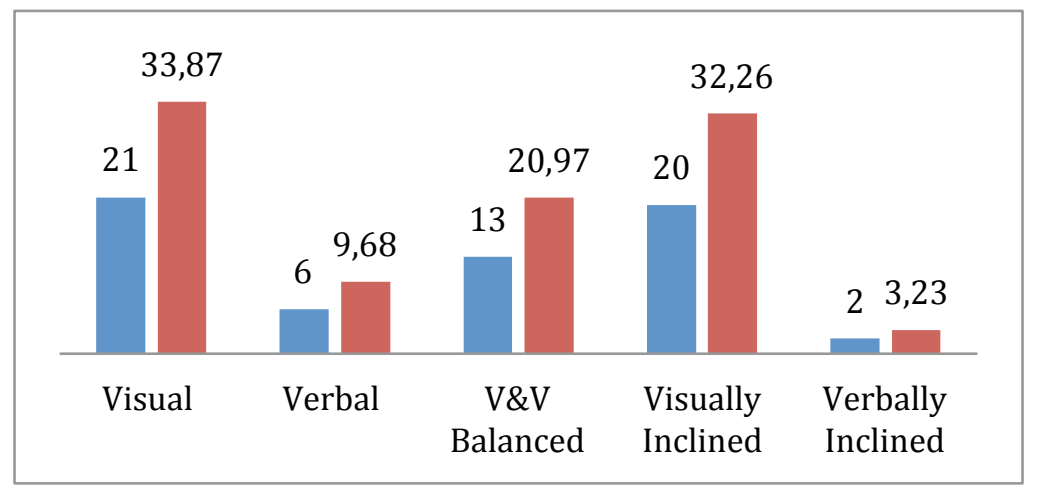

Graph 1: Learner Preferences in Manual V-Square Test

\subsection{Results of V-Square test on system}

As shown in Graph 2 the visual learning style cluster contains 19 learners, verbal learning style cluster contains 07 learners and remain 36 learners which have moderate preferences on both dimensions are grouped in balanced cluster as mentioned in section 5.2. 30.65\% learners were identified as visual learners, whereas $11.29 \%$ learners were having strong preference in verbal dimensions. The results show that maximum learners i.e. $58.06 \%$ have moderate preference on the visual and verbal dimensions.

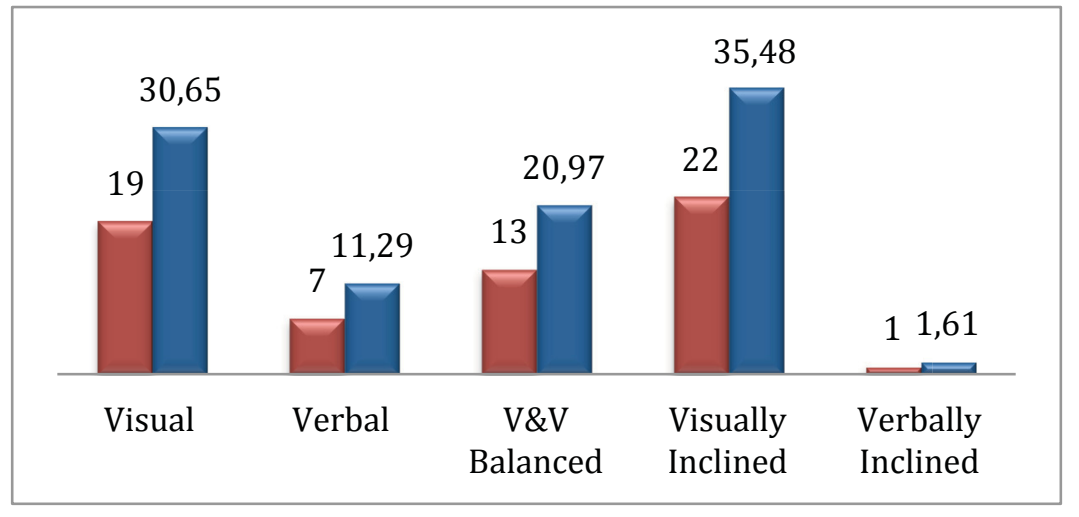

Graph 2: Learner Preferences in Manual V-Square Test 


\subsection{Results of Manual LST Test}

Learning strategy test (LST) is given to all 62 participants after completion of VSquare test. After calculation of results of VST, the results of LST are arranged according to three learner style clusters as shown in table 6 . In cluster of visual learner $4.76 \%$ learner are active learner, there is no active reader and 95.24\% learner has moderate preference for listening and reading. In cluster of verbal learner $16.67 \%$ learners are active listener, there is no active reader and $83.33 \%$ learners have moderate preference for listening and reading. The cluster of balanced learning style includes $2.86 \%$ learners as active listeners and $2.86 \%$ learners as active readers whereas $94.28 \%$ learners like to read and listen.

Table 6. Learning Strategies of Visual, Verbal and Balanced Learners.

\begin{tabular}{|c|c|c|c|c|c|c|}
\hline \multirow{2}{*}{ Learner Style Cluster } & \multicolumn{2}{|c|}{$\begin{array}{l}\text { Active Listener } \\
\text { (AL) }\end{array}$} & \multicolumn{2}{|c|}{ Active Reader (AR) } & \multicolumn{2}{|c|}{$\begin{array}{c}\text { Listener \& Reader } \\
\text { (BLR) }\end{array}$} \\
\hline & No. & $\%$ & No. & $\%$ & No. & $\%$ \\
\hline Visual $(\mathrm{N}=21)$ & 01 & 4.76 & 00 & 0.0 & 20 & 95.24 \\
\hline Verbal $(\mathrm{N}=06)$ & 01 & 16.67 & 00 & 0.0 & 05 & 83.33 \\
\hline Balanced $(\mathrm{N}=35)$ & 01 & 2.86 & 01 & 2.86 & 33 & 94.28 \\
\hline
\end{tabular}

\subsection{Results of LST test on system}

Once the learner completes the V-Square Test, the web based tool presents the LST test to learner. On completion of test the algorithm identifies the learning strategy of learner and assigns it to a learner. As shown in table 7 all the learners in visual cluster are balanced listener and reader. The cluster of verbal learner contains $14.29 \%$ active listeners and $85.71 \%$ balanced listeners and readers. The cluster of balanced learner contains $2.78 \%$ active listeners and readers, $94.44 \%$ balanced listeners and readers.

Table 7. Learning Strategies of Visual, Verbal and Balanced Learners.

\begin{tabular}{|l|c|c|c|c|c|c|}
\hline \multirow{2}{*}{ Learning Strategy } & \multicolumn{2}{|c|}{$\begin{array}{c}\text { Active Listener } \\
\text { (AL) }\end{array}$} & \multicolumn{2}{c|}{ Active Reader (AR) } & \multicolumn{2}{c|}{$\begin{array}{c}\text { Listener \& Reader } \\
\text { (BLR) }\end{array}$} \\
\cline { 2 - 7 } & No. & $\%$ & No. & $\%$ & No. & $\%$ \\
\hline Visual (N=19) & 00 & 0.0 & 00 & 0.0 & 19 & 100 \\
\hline Verbal (N =07) & 01 & 14.29 & 00 & 0.0 & 06 & 85.71 \\
\hline Balanced (N=36) & 01 & 2.78 & 01 & 2.78 & 34 & 94.44 \\
\hline
\end{tabular}

Reliability of Multimodal Approach. Test-Retest Reliability is found using Pearson Correlation Coefficient " $r$ " is calculated with following formula. The duration between two test was 15 days.

$$
r=\frac{n\left(\sum x y\right)-\left(\sum x\right)\left(\sum y\right)}{\sqrt{\left[n \Sigma x^{2}-(\Sigma x)^{2}\right]\left[n \sum y^{2}-(\Sigma y)^{2}\right]}}
$$


Where,

$\mathrm{n}=$ number of learners

$\Sigma \mathrm{x}=$ sum of $\mathrm{x}$ scores in test 1

$\Sigma y=$ sum of $y$ scores in test 2

$\Sigma x y=$ sum of the products of paired scores

$\Sigma \mathrm{x} 2=$ sum of squared $\mathrm{x}$ scores

$\Sigma \mathrm{y} 2=$ sum of squared $\mathrm{y}$ scores

The V-Square Test is found reliable with $\mathrm{r}=0.9966$ indicating the strong positive correlation. The LST test is found reliable with $\mathrm{r}=0.9904$ indicating the strong positive correlation. Over a period of time the learner style may change hence a mechanism that records the learning object access patterns of learners in a web based eLearning environment will be developed in future.

\section{Conclusion}

The results clearly show that the number of learners having strong preferences for visual and verbal learning dimensions of FSLSM is quite less. More than $50 \%$ learners are identified as having moderate preference for visual and verbal learning dimensions of FSLSM.

The results of Learning strategy test show that more than $80 \%$ learners like to read and listen when learning. Hence an eLearning environment must provide the opportunities to learners for reading and listening.

The reliability of the proposed framework was tested using Pearson Correlation Coefficient. The V-Square Test is found reliable with $r=0.9966$ indicating the strong positive correlation. The LST test is found reliable with $\mathrm{r}=0.9904$ indicating the strong positive correlation.

There were very slight differences were found in manual test and system test. Even though the duration of retest was 15 days after the first test few learners have changed their answers either intentionally or unintentionally. This indicates that the learner style may change over the time. In future, we will try to observe and overcome this problem. Learner assessment techniques are also important while assessing the performance of learner in an eLearning environment or Instructor Led Classroom environment in future learning assessment strategies of visual and verbal learners can be explored to enhance learning efficiency and learning experience of learners in a web based eLearning environment.

\section{References}

[1] Richard M. Felder, and Linda K. Silverman, "Learning and Teaching Styles in Engineering Education", Engineering Education, Vol. 78, No. 7, 1988, pp. 674-681.

[2] Richard M. Felder Author's Preface - June 2002 http://www4.ncsu.edu/unity/lockers/users/ f/felder/public/Papers/LS-1988.pdf 
Paper-Multimodal Approach to Identify Learning Strategies of Visual and Verbal Learners

[3] Richard M. Felder "Learning Styles and Strategies" A four-page handout that briefly explains the learning style preferences defined by the Felder-Silverman model. http://www4.ncsu.edu/unity/lockers/users/f/felder/public/ILSdir/styles.pdf

[4] Index of Learning Style (ILS) available online at http://www4.ncsu.edu/unity/lockers/ users/f/felder/public/ILSpage.html

[5] Felder, R.M., Solomon, B.A., http://www.engr.ncsu.edu/learningstyles/ilsweb.html.

[6] ILS Questionnaire, ILS Scoring Sheet, ILS Report form available online in .pdf format at http://www.physics.rutgers.edu/deltap/ILS.pdf

[7] Malgorzata S. Zywno "A Contribution to Validation of Score Meaning for FelderSoloman's Index of Learning Styles", Proceedings of the 2003 American Society for Engineering Education Annual Conference \& Exposition Copyright (C) 2003, American Society for Engineering Education.

[8] Richard M. Felder and Joni Spurlin "Applications, Reliability and Validity of Index of Learning Styles", International Journal of Engineering Education, Vol. 21, No. 1, pp 103$112,2005$.

[9] Thomas A. Litzinger, Sang Ha Lee, John C. Wise, Richard M. "A Psychometric Study of the Index of Learning Styles” Journal of Engineering Education, 96(4), 309-319 (2007). https://doi.org/10.1002/j.2168-9830.2007.tb00941.x

[10] Richard M. Felder "ARE LEARNING STYLES INVALID? (HINT: NO!)”, On-Course Newsletter, September 27, 2010.

[11] Fleming, N. D. and Mills, C. (1992), "Not Another Inventory, Rather a Catalyst for Reflection", To Improve the Academy, Vol. 11, 1992. http://digitalcommons.unl.edu/cgi/ viewcontent.cgi?article=1245\&context=podimproveacad https://doi.org/10.1002/j.23344822.1992.tb00213.x

[12] Neil Fleming "Teaching and Learning Styles - VARK Strategies", Revised and reprinted April 2012. ISBN Number: ISBN 978-0-473-07956-7

[13] Ahmed Al-Azawei and Atta Badii, STATE OF THE ART OF LEARNING STYLESBASED ADAPTIVE EDUCATIONAL HYPERMEDIA SYSTEMS (LS-BAEHSS) International Journal of Computer Science \& Information Technology (IJCSIT) Vol 6, No 3, June 2014.

[14] Simon Casidy "Learning Styles: An overview of theories, models and measures", Educational Psychology, Vol. 24, No. 4, August 2004. ISSN 0144-3410 (print) / ISSN 1469046X (online) / 04/030419-26.

[15] Alharbi, A., Paul, D., Henskens, F. \& Hannaford, M. (2011). An investigation into the learning styles and self-regulated learning strategies for Computer Science students. In G.Williams, P. Statham, N. Brown \& B. Cleland (Eds.) Changing Demands, Changing Directions. Proceedings ascilite Hobart 2011. (pp.36-46). http://www.ascilite.org.au/ conference/hobart11/procs/Alharbi-full.pdf

[16] Silvia Rita Viola, Sabine Graf, Kinshuk, Tommaso Leo "Analysis of Felder-Silverman Index of Learning Styles by a Data-driven Statistical Approach".

[17] Norasmah Othman, Mohd Hasril Amiruddin "Different Perspectives of Learning Styles from VARK Model", International Conference on Learner Diversity 2010, Procedia Social and Behavioral Sciences 7(C) (2010) 652-660, 1877-0428 (C) 2010 Published by Elsevier Ltd.

[18] Burcu Devrim Ictenbas, Hande Eryilmaz "Determining Learning Styles of Engineering Students to Improve the Design of a Service Course", Procedia - Social and Behavioral Sciences 28 (2011) 342 - 346, 1877-0428 (C) 2011 Published by Elsevier Ltd. https://doi.org/10.1016/j.sbspro.2010.10.088 
[19] Julie Willems "Using learning styles data to inform e-learning design: A study comparing undergraduates, postgraduates and e-educators", Australasian Journal of Educational Technology 2011, 27(6), 863-880. https://doi.org/10.1016/j.sbspro.2011.11.065

[20] Pham Quang Dung, Adina Magda Florea "An approach for detecting learning styles in learning management systems based on learners' behaviours", 2012 International Conference on Education and Management Innovation IPEDR vol.30 (2012) (C) (2012) IACSIT Press, Singapore. https://doi.org/10.14742/ajet.917

[21] Thomas Lehmann and Dirk Ifenthaler, "INFLUENCE OF STUDENTS' LEARNING STYLES ON THE EFFECTIVENESS OF INSTRUCTIONAL INTERVENTIONS", IADIS International Conference on Cognition and Exploratory Learning in Digital Age (CELDA 2012), ISBN: 978-989-8533-12-8 C 2012 IADIS.

[22] Emel ULTANIR, Y. Gurcan ULTANIR, and Gülhan OREKECI TEMEL, "The Examination of University Students' Learning Styles by Means of Felder-Silverman Index”, 2012, Cilt 37, Say1 163, Education and Science 2012, Vol. 37, No 163.

[23] Maryam Yarandi, Hossein Jahankhani, Abdel-Rahman H. Tawil, "A personalized adaptive e-learning approach based on semantic web technology", Webology, Volume 10, Number 2, December, 2013.

[24] Juan Yang, Zhi Xing Huang, Yue Xiang Gao, and Hong Tao Liu "Dynamic Learning Style Prediction Method Based on a Pattern Recognition Technique", IEEE TRANSACTIONS ON LEARNING TECHNOLOGIES, VOL. 7, NO. 2, APRIL-JUNE 2014.

[25] Jennifer Beckmann, Sven Bertel, Steffi Zander "Adaptive eLearning based on individual learning styles - Performance and emotional factors", M. Koch, A. Butz \& J. Schlichter (Hrsg.): Mensch und Computer 2014 Tagungsband, München: Oldenbourg Wissenschaftsverlag, 2014, S. 287-290.

[26] Milan Klement "How do my students study? An analysis of students` of educational disciplines favorite learning styles according to VARK classification”, 6th International Conference on Intercultural Education "Education and Health: From a transcultural perspective", Procedia - Social and Behavioral Sciences 132 (2014) $384-390.1877-0428$ (C) 2014 The Authors. Published by Elsevier Ltd. https://doi.org/10.1524/9783110344486.287

[27] Jingyun Wang, Takahiko Mendori "The Reliability and Validity of Felder- Silverman Index of Learning Styles in Mandarin Version", Information Engineering Express International Institute of Applied Informatics 2015, Vol.1, No.3, 1 - 8 .

[28] S. Muruganandam and N. Srinivasan, "Appraisal of Felder - Silverman Learning Style Model with Discrete Data Sets", Indian Journal of Science and Technology, Vol 9 (10) | March 2016 | www.indjst.org, ISSN (Print): 0974-6846 ISSN (Online): 0974-5645.

[29] M. Prabhani Pitigala Liyanage, K. S. Lasith Gunawardena, Masahito Hirakawa "Using Learning Styles to Enhance Learning Management Systems", Using Learning Styles to Enhance Learning Management Systems, International Journal on Advances in ICT for Emerging Regions 201407 (02).

[30] Jennifer Beckmann, Sven Bertel and Steffi Zander, "PERFORMANCE \& EMOTION - A STUDY ON ADAPTIVE E-LEARNING BASED ON VISUAL/VERBAL LEARNING STYLES”, International Conference e-Learning 2015, ISBN: 978-989-8533-40-1 C 2015.

[31] Solmaz Zarei, Ali Roohani, Ali Akbar Jafarpour, "The Effect of Visual/Verbal Learning Style on Reading Comprehension", International Journal of Educational Investigations Vol.2, No.6: 10-19, 2015 (June) ISSN: 2410-3446.

[32] Manal Abdullah and etl... "The Impact of Learning Styles on Learner's Performance in ELearning Environment", (IJACSA) International Journal of Advanced Computer Science and Applications, Vol. 6, No. 9, 2015. 
[33] Yi-Hsing Chang \& Yen-Yi Chen, "Yet another adaptive learning management system based on Felder and Silverman's learning styles and Mashup", Eurasia Journal of Mathematics, Science \& Technology Education, 2016, 12(5), 1273-1285 https://doi.org/10.12973/eurasia.2016.1512a

[34] Mahendra A Sethi, S.S. Lomte, U.B. Shinde "Adaptive eLearning System for Visual and Verbal Learners", 2016 International Conference on Computing for Sustainable Global Development(INDIACom), 978-9-3805-4421-2/16/\$31.00 (2016 IEEE.

[35] Mohd Pouzi Hamzah, Wan Fatin Fatihah Yahya, Noor Maizura Mohamad Noor, Mohamad "LEARNING STYLE DETECTION BY USING LITERATUREBASED APPROACH: A CONCEPTUAL DESIGN", International Symposium on Research in Innovation and Sustainability 2014 (ISoRIS '14) 15-16 October 2014, Malacca, Malaysia, Sci.Int.(Lahore),26(4),1493-1497,2014 ISSN 1013-5316; CODEN: SINTE 8.

[36] Hadeel Ateia and Thair Hamtini "Designing and Implementing of Dynamic Technique for Detecting Learning Style Using Literature Based Approach", International Journal of Database Theory and Application Vol.9, No.6 (2016), pp. 9-20. https://doi.org/10.14257/ijdta.2016.9.6.02

[37] M S Hasibuan, LE Nugroho, P I Santosa, S S Kusumawardani "A Proposed Model for Detecting Learning Styles Based on Agent Learnin”, iJET - Volume 11, Issue 10, 2016.

\section{Authors}

Mahendra A Sethi is research student at Department of Computer Science \& Information Technology and currently working as Head of Center for Technical Skills \& Entrepreneurship in CSMSS Chh. Shahu College of Engineering Aurangabad, India.

Santosh S Lomte is a computer scientist, engineering educator, and Principal at VDF School of Engineering and Technology Latur, India.

Ulhas B Shinde received PhD Degree in Electronics \& Telecommunication Engg, $\mathrm{He}$ is an engineering educator, and Principal at CSMSS Chh. Shahu College of Engineering Aurangabad, India. He worked as a Dean, Faculty of Engineering and Technology in Dr. B.A.M.University and initiated notable changes in curriculum by introducing open elective subjects to bridge the gap between industry and academics. He is a recipient of award "Excellence in academics \& innovation" in year 2017.

Article submitted 20 March 2017. Published as resubmitted by the authors 17 May 2017. 